3. Bulanin D.M. Evfimii, cellarer of the Chudov Monastery. Slovar knizhnikov i knizhnosty Drevnej Rusi. St. Petersburg, 2004, iss. 3, pt. 4, pp. 695-698. (In Russ.)

4. Sazonova L.I. Russian literary culture. Early Modern Times. Moscow, 2006, 894 p. (In Russ.)

5. Isachenko T.A. Moscow book learning in translation. Metropolitan and patriarchal scriptorium of the XV-XVII centuries. Moscow, 2009, 334 p. (In Russ.)

6. Florovsky A.V. Chudovsky monk Evfimii: One of the last advocates of the "Greek doctrine" in Moscow. Slavia. Praha, 1949, vol. 19, pp. 100-152. (In Russ.)

7. Fonkich B.L. Greek book writing in Russia in the XVII century. Knizhnye centry Drevnej Rusi: XVII wek. Rasnye aspekty issledovanija. St. Petersburg, 1994. (In Russ.)

8. Panich T.V. Writers of the Patriarch circle in the theological polemics of the $80 \mathrm{~s}-90$ s of the XVII century: abstracts of thesis ... Doctor of Philological Sciences. Novosibirsk, 2007. (In Russ.)

9. Prozorovsky A.A. Sylvester Medvedev (his life and activity) the experience of church-historical research. Moscow, 1896. (In Russ.)

10. Panich T.V. Book "Shield of Faith" in the historical-literary context of the late XVII century. Novosibirsk, 2004. 327 pp. (In Russ.)
11. Panich T.V. Patriarch Adrian's letter on book "Shield of Faith" edition. Cultura, Istoriya i Literatura Russkogo mira: obschenacionalnyj i regionalnyj aspecty. Sbornik statej i materialov vserossijskoj nauchnoj conferencii s mezhdunarodnym uchastiem "Chelovek i mir cheloveka." Barnaul, 2014. pp. 316-334. (In Russ.)

12. Bernatsky M.M. Council of Constantinople in 1691 and its reception in the Russian Orthodox Church (on the problem of a canonical status of term "transubstantiation"). Bogoslovskie trudy. Moscow, 2007. N 41, pp. 138-144. (In Russ.)

13. Panich T.V. Evfimii Chudovsky's "answer" to the "lying writing" by Petr Artemyev. Obschestvennoje soznanie i literatura XVI$X X v v$. Novosibirsk, 2001. pp. 224-245. (In Russ.)

14. Isachenko T.A. Faith and defiance in the responses and refutations in 80-90s of the XVII century: new Bible translations in philological schools of the XVII century. Moscow, 2015. 382 pp. (In Russ.)

15. Panich T.V. The complex of handwritten materials relating to the affairs of Peter Artemiev and Gregory Skibinsky (textual observation). Obschestvennoje soznanie i literatura Rossii: istochniki $i$ issledovaniya. Novosibirsk, 2008, pp. 30-53. (In Russ.)

\title{
М.В. ПЕРШИНА
}

\section{О «БЕСЕДАХ» ТЮМЕНСКОГО СТАРООБРЯДЦА В.И. МАКАРОВА*}

\author{
Мария Валерьевна Першина, \\ канд. ист. наук, доцент, \\ Сибирский учебный научный центр Новосибирского национального \\ исследовательского государственного университета, \\ РФ, 630090, г. Новосибирск, ул. Ляпунова, 3, \\ e-mail: masha@perchine.com
}

\begin{abstract}
В статье анализируются сочинения руководителя общины тюменских старообрядцев-филипповцев последней четверти ХІХ - начала XX в. В.И. Макарова, написанные в форме «бесед». Установлено, что в основе большинства из них лежали реальные дискуссии наставника с лидерами других согласий и миссионерами официальной Церкви. Анализ составленного Макаровым руководства для участников прений позволил уточнить его представление о том, как должен был быть организован этот процесс, и проследить практическую реализацию этих рекомендаций. Сделан вывод о том, что «беседы» были важным аспектом религиозной и культурной жизни местной старообрядческой общины.
\end{abstract}

Ключевые слова: старообрядчество, полемика, сочинения, «беседы», старообядческая община, филипповиьл.

\section{M.V. PERSHINA}

\section{ON "DIALOGUES" BY V.I. MAKAROV, A TYUMEN OLD-BELIEVER}

\author{
Maria V. Pershina, \\ Candidate of Historical Sciences, \\ Siberian Education and Scientific Center, Novosibirsk State University, \\ 3 Lyapunov Str., Novosibirsk, 630090, Russia \\ e-mail:masha@perchine.com
}

\footnotetext{
*Статья подготовлена при финансовой поддержке РГНФ, проект № 14-01-00217.
} 
The manuscript collection compiled by V.I. Makarov, a leader of Tyumen community of Philipovtsy Old-Believers in the late XIX - early XX centuries, is kept in the fonds of the Institute of History of the Siberian Branch of the Russian Academy of Sciences. It includes a wide range of writings in the form of dialogues between a "nastavnik" (church leader, preceptor) with opponents representing the official church or other denominations. These "dialogue" writings were based on the disputes that had really taken place. Analysis of Makarov's guidelines helped to clarify his views on how the disputes should be arranged. The author determined the speakers' position during the discussion, the speaking order, established rules for the spectators' behaviour. Descriptions of some specific «conversations» included into collections by Makarov show that participants in fact did not always follow the proposed rules. An attempt of the leader of Tymen Philippovtsy to regulate and control an unpredictable emotional process of disputes is a valuable evidence of the community's intensive inner life.

Texts describing the most interest disputes were copied and distributed among Old-Believers as well as sent to other regions. On the basis of an analysis of the texts of certain "dialogues" a conclusion was made that although these texts contained many quotes and references to appropriate book chapters, they were written in the language of "colloquial speech" and meant for reading aloud. Lots of moral adages about a true Christian's mortal life and destination show that the author addressed not the opponents but mostly the Old-Believers of his own community. The "dialogues" were a convenient excuse for preaching aimed a t establishing his coreligionists in their faith.

Key words: Old-Believers, polemics, writings, "dialogues”.

С момента раскола Русской Церкви защитники старого обряда вынуждены были отстаивать свою точку зрения в прениях, дискуссиях с представителями официальной православной Церкви, а с начала XVIII в. и с лидерами других согласий, на которые стало делиться это движение. В связи с необходимостью вести полемику распространенным жанром у старообрядцев становятся «Беседы» или «Беседословия», которые представляли собой диалог автора с реальным или воображаемым оппонентом. Это позволяло представить не только авторскую точку зрения по конкретному вопросу, но и его оппонента и в зависимости от позиции автора убедить читателя в «истинности» одной из них. Иногда для этого автор цитировал фрагменты сочинения оппонента. В некоторых случаях написанию «Беседословия» предшествовала реальная многочасовая дискуссия. Подобные «беседы» проводились обычно в присутствии зрителей, собравшихся из разных мест послушать старообрядческих ораторов и принять участие в полемике. Попытаемся охарактеризовать словесные состязания, в которых принимал участие опытный полемист, возглавлявший в последней четверти XIX в. общину тюменских филипповцев, Варсонофий Иванович Макаров $[1 ; 2 ; 3]$.

В рукописном комплексе из собрания Института истории СО РАН, составленном этим выдающимся деятелем тюменского старообрядчества ${ }^{1}$, сочинения в форме «бесед» представлены достаточно широко. Макаров включил в сборники описание дискуссий со своими единоверцами, странниками, федосеевцами, «немоляками», поморцами, представителями белокриницкого согласия, единоверческой Церкви и миссионерами синодальной Церкви [4]. Судя по тому, что он сообщал конкретные даты прений, в основе многих его «беседословий» лежали реально состоявшиеся словесные поединки старообрядческих ораторов.

Некоторое представление о том, как проводились такого рода мероприятия, позволяет получить небольшое сочинение, включенное в первый том тюменского рукописного свода. Оно представляет собой руководство для участников «бесед», оформленное в виде

${ }^{1}$ Собрание Института истории СО РАН, № 13/74, 14/74, 2/77. (Далее - Собрание ИИ СО РАН).
26 статей. В начале сочинения помещено следующее обращение: «Честнейшии отцы и все честное собрание, нельзя ли принять в пример условие беседе, на каких основаниях быть любовно по обычном начале и по благословении» ${ }^{2}$. Помещенные далее правила участникам собрания предлагалось принять в качестве образца, как проводить беседу «любовно».

В сочинении не указаны ни автор, ни время его написания, но с определенной долей вероятности можно утверждать, что оно написано самим составителем сборника в 70-е гг. XIX в. (не позднее 1878 г.). В это время Варсонофий Иванович стал наставником тюменских филипповцев и организовал серию соборов в местечке Пашенка (в 30 км от Тюмени) с целью детальной регламентации всех сторон жизни общины и утверждения обязанностей наставника [4]. Попытка установить четкие правила для проведения «бесед» была в русле общей организационной деятельности Макарова.

В первой статье речь шла о главных участниках дискуссиии - определялось их расположение во время «беседы»: «Беседовать одному на занимательном месте к прям седящему лицу, а не к слышателем, тако по сторонам не озираяся» ${ }^{3}$. Ораторы должны были сидеть напротив друг друга отдельно от зрителей, при обращении к оппоненту им нельзя было переходить на другое место в поиске поддержки и одобрения своими единоверцами. Особо оговаривалось, что обе стороны обладают равными правами.

В тексте не определен временной регламент выступлений, очевидно, автор подразумевал, что обстановка должна была располагать к тому, чтобы участники имели возможность высказаться без ограничений: «Седящее лице изменится, как только... по изнеможению его» ${ }^{4}$. Эта статья зафиксировала реальную практику многочасовых дискуссий, которые длились «до изнеможения» ораторов. В старообрядческих сочинениях есть упоминания о том, что даже если в отдельных случаях и вводились ограничения на время выступлений, они были такими, что позволяли ораторам «выговориться».

В более позднее время регламент выступлений конкретизировался. Например, во введении к публи-

${ }^{2}$ Собрание ИИ СО РАН, № 13/74. Л. 819 об.

3 Там же, л. 819 об.

4 Там же, л. 820. 
кации «беседы» Л.Ф. Пичугина, Ф.Е. Мельникова и Д.С. Варакина, состоявшейся 7-10 мая 1909 г. в Москве, регламент для выступающих был определен следующим образом: «Каждыи собеседник должен говорить речь не более 30 -ти минут, таких речей на каждаго собеседника приходилось по четыре, пятая речь собеседника, начинающаго беседу, должна быть не более 20 -ти минут, последняя речь заканчивающаго собеседника не должна превышать 10-ть минут» [5]. Таким образом, каждому участнику дискуссии предоставлялось в общей сложности более 2,5 ч на выступление, не считая ответов на вопросы.

В ряде статей тюменского сочинения о правилах ведения бесед говорилось не только о необходимости уважительного отношения к собеседнику, но и к книгам: «Книгу или статью един другому подавать с кротостию, а с яростию не брать и не вырывать другому, но кротко примать и подавать» ${ }^{5}$. О книгах было упомянуто не случайно - они являлись важным атрибутом любой беседы. Статья 21-я предписывала: «Наизусть статей или глав не читати, разве только за необходимость в кратком пояснении в беседе или за крайнюю невозможность тоя главизны достати» ${ }^{6}$. В этой статье явно нашла отражение существующая практика: любое высказывание старообрядцы подтверждали соответствующими цитатами из заранее подготовленных книг.

В литературе встречаются упоминания о том, что в ходе прений участники в случае необходимости в кратчайший срок приносили дополнительно книги, чтобы подкрепить свои аргументы авторитетными текстами. Например, как сообщил тюменский миссионер К. Беллюсов, побывавший на «беседе» в с. Исетском в 1890 г., один из оппонентов В.И. Макарова, поморец Ефим Андреевич Сидоров, «потребовал лошадь и довольно скоро съездил домой в деревню Пастухову... и привез два узла старопечатных книг, которые разложил в достодолжном порядке» [6, с. 256].

Определив правила поведения главных участников полемики, автор сочинения перешел к регламентации поведения зрителей. Он предлагал «слушающим седеть с молчанием», а если не согласны с ораторами, «во оказывающихся сопротивностях являть терпимости, избегая насмешик и руганиев» и «со всевозможностию удерживаться от смеха». Судя по этим замечаниям, зрители обычно живо следили за ходом беседы и эмоционально реагировали на происходящее. Повидимому, чтобы обеспечить соответствующую обстановку для ведения дискуссии, в правилах предлагалось после выступления главных ораторов давать право на высказывание собственной точки зрения только тем слушателям, которые не нарушали порядка и вели себя «кротимо», т.е. спокойно: «Желающему и могущему законно вступити на смену, седящаго кротимо, допускать, а не сумевшаго кротимо, унимать» 7 .

\footnotetext{
5 Там же, л. 820 об.

${ }^{6}$ Там же.

${ }^{7}$ Там же, л. 820 .
}

Составитель статей рассчитывал на то, что желание высказаться публично у наиболее активных слушателей могло быть настолько велико, что должно было восприниматься в качестве сдерживающего фактора. Впрочем, заключительные строки сочинения свидетельствуют о том, что сам автор, неоднократно присутствующий на подобных беседах, был реалистом и не был вполне уверен, что во время ожесточенного спора о вере и истине зрители смогут спокойно и беспристрастно слушать ораторов. Об этом свидетельствует статья, предписывающая наказание для присутствующих на беседе: «В нарушении условленных правил, по первом нарушении, мощно рещи: «Хорошо ли не соблюдать условие?» По десяти несоблюдениих - наказание с милостию» ${ }^{8}$. Здесь явно нашла отражение реальная практика ведения дискуссий. По предлагаемым правилам слушатель только после 10 предупреждений мог быть подвергнут «наказанию с милостию», т.е. достаточно мягкому.

Попытка наставника тюменских филипповцев регламентировать порядок проведения словесных поединков, взять под контроль непредсказуемый и эмоционально насыщенный процесс прений является ценным свидетельством интенсивности внутренней жизни общины. Описания некоторых конкретных бесед, помещенных Макаровым в сборники, свидетельствуют, что в действительности предложенные правила выполнялись далеко не всегда. В частности, он в нескольких сочинениях различного жанра, включенных в четвертый том тюменского рукописного свода [7], упоминает о беседе, на которой, с точки зрения Варсонофия Ивановича, были грубо нарушены предложенные им правила.

Беседа состоялась 23 мая 1895 г. в Таватуе, где Макаров проживал в тот момент. Поводом к ней послужило принятие наставником на общее моление нескольких «новоженов». Часть общинников, вероятно «новоженов», была недовольна тем, что подобная практика не станет правилом, другая же придерживалась традиционных для старообрядцев-безбрачников взглядов. Обе группы таватуйских общинников, недовольных своим наставником, обратились за советом к Ивану Андреевичу Воробьеву, который согласился обсудить публично этот вопрос. На беседу с Макаровым в молитвенный дом он пришел, пригласив и волостное начальство. В письме в Москву Варсонофий Иванович так описал эту ситуацию: «Того же мая месяца в 23 день под изветом, бутьто бы совет со мной чинить, пришли в молитвенный дом с канвоем в числе человек 50: волостной староста и сотской с десятниками со обнаженными знаками, а с ними Воробьев, Кокушкин и Яков Ильин»?.

Автор письма акцентировал внимание на агрессивности пришедших: «Кричали: «Стой, стой, молчи, пускай Иван Андреевичь (Воробьев. - М.П.) чи-

\footnotetext{
8 Там же, л. 820 об.

9 Тюменский областной краеведческий музей им. И.Я. Словцова. Собрание рукописей. КП 9201/2. Л. 905.
} 
тат». Вместо мирной беседы, на что рассчитывал Макаров, пришедшие якобы начали зачитывать заранее заготовленный текст с обвинениями наставнику. Вот как описана эта ситуация в письме: «А он (Воробьев. - М.П.) отличился тогда и говорил: “Ты 10 лет читал, а теперь я читаю”, - и читал свои складни. Прочитал времени часа за два, а мне никакого ответу подать не дали: как начну что говорить, то подымат крик. Потом пошли из моленной с наругательством, что дедушко против Ивана Андреевича никакого ответа не мог подати». Закончилось дело изгнанием наставника: «Потом 25 мая через волостной суд меня ис Таватуя выгнали» ${ }^{10}$.

Описывая эту неудачную «беседу», наставник, по-видимому, стремился на собственном примере показать читателям, к каким последствиям может привести нарушение правил ведения дискуссии, и предостеречь их от подобных ошибок. Но еще большее внимание старообрядцы уделяли «беседам», которые воспринимались ими как «удачные». Тексты с их описаниями копировались, распространялись среди единоверцев, посылались в другие регионы. Особое место среди них занимают описания прений с миссионерами официальной Церкви, которые массово стали проводиться с 60-х гг. ХІХ в., когда в связи с относительной либерализацией правительственного курса в отношении старообрядцев и изменением карательной тактики на практику «увещеваний» началась планомерная миссионерская деятельность приходских священников.

В сборнике 2/77 из собрания ИИ СО РАН содержится описание двух «бесед» защитника старого обряда с миссионером. Обе они носят похожие названия - «Беседа опытнаго человека от числа ученых и образованных людей с простецом, состоящим во обрядах староцерковных» и «Собеседование краткоответственное, писанное человеком простецом на предлоги, имеющиеся в числе 25-ти пунктов, написаны достопочтеннейшим человеком от числа ученых и образованных людей» ${ }^{11}$. Имена участников этих «бесед» не названы, но судя по тому, что в текстах фигурируют «простец» и «ученый и образованный человек», речь идет об одних и тех же людях.

В конце второго «собеседования» имеется приписка рукой В.И. Макарова: «Переписаны по гладе вышеявленныя вопросо-ответы 1886 лета, сентября 3-го, а подаваны были раньше, как около двух или как годов» ${ }^{12}$, т.е. сочинение написано было не позднее 1884 г. Вполне возможно, в 1886 г. оно стало вновь актуально для филипповской общины в связи с началом миссионерской деятельности К. Беллюсова. Его предшественником на этом поприще был настоятель тюменской Троице-Никольской единоверческой церкви протоиерей Христофор Иваницкий. Как выяснила современная исследовательница

\footnotetext{
${ }^{10}$ Там же. Л. 905-905 об.

${ }^{11}$ Собрание ИИ СО РАН, № 2/77, л. 87-95, 697-721 об.

12 Там же, л. 721 об.
}

Л.Н. Суслова, за усердную службу и за борьбу с расколом он трижды получал благодарности от Синода и Тобольского архиепископа, был награжден набедренником, скуфьей, камилавкой, двумя бронзовыми наперсными крестами на Владимирской ленте, двумя знаками Красного Креста, орденом Святой Анны третьей и второй степеней и, наконец, уже в конце своей службы «по ходатайству причтов единоверческих церквей Тобольской епархии и Тобольского Епископа Антония», «за свыше пятидесятилетние труды в сане священника» был награжден палицей $[8$, c. 215,229$]$. Такое обилие знаков отличия вполне позволяло старообрядческому автору назвать его «достопочтеннейшим человеком от числа ученых и образованных людей». Кроме того, в периодическом издании «Истина» за 1883 г. в разделе «Миссионерская переписка» опубликованы его ответы на вопросы «тюменского мещанина» Варсонофия Иванова Макарова [9]. В публикации содержится продолжение полемики по вопросам, затронутым в «беседах» из тюменского сборника, это позволяет отождествить «простеца» с В.И. Макаровым, а «человека ученаго» с X. Иваницким.

В заглавии сочинений с описанием бесед с миссионером старообрядческий автор выделил важную проблему, которая поднимается в этих текстах - противопоставление образованности, учености и «простоты». Эта проблема была поставлена еще в сочинениях лидеров раннего этапа старообрядческого движения и продолжена в трудах писателей выговской литературной школы. Исследования Н.В. Понырко [10], Е.М. Юхименко [11] и О.Д. Журавель [12, c. 10-21] показали, что старообрядцы признавали два пути познания истины: через книжную премудрость и через Божественное откровение. В XVIII в. в богословско-полемических сочинениях выговцев, написанных в рационалистическую Петровскую эпоху, больше прослеживалась ориентация на риторики и книжное любомудрие [12, с. 10-21].

В «Беседе опытнаго человека от числа ученых и образованных людей с простецом...» эта тема получила дальнейшее развитие. Поводом для рассуждений тюменского старообрядца об «учености» стал вопрос миссионера, который он сформулировал так: «Ты, старичек, понимаешь о православной нашей Церкви и пастырех..., что у нас теперь все безблагодатно. Но веть нынешний народ ученой, прошли высокия науки. И неужели жо простой старик, сидя во углу за печью, и мог узнать правду, а ученыя люди, архиереи, епископы, митрополиты прошли курсы наук и против бы старика неученаго не могли бы знать? Етова быть не может» ${ }^{13}$. Выступая в защиту «простецов», не имевших образования, В.И. Макаров приводит 12 свидетельств «сбывшихся пророчеств» о рождении и жизни Исуса Христа из Священного Писания и Предания, полученных в разные времена разными людьми исключительно по божественному открове-

\footnotetext{
13 Там же, л. 90.
} 
нию. Он подчеркивает, что эти знания не были результатом работы рассудочного ума образованных людей, а были дарованы свыше, увидены духовным зрением, и потому они - истинные.

Однако будучи человеком Нового времени, книжником, владельцем большой библиотеки, в которую входили не только старопечатные и рукописные книги, но и произведения современных авторов, старообрядец не мог, подобно протопопу Аввакуму, полностью отрицать истинность «книжных», приобретенных знаний. Обращает на себя внимание тот факт, что «беседа» изобилует нравоучительными сентенциями, которые обращены не только к оппоненту-миссионеру, но прежде всего к читателям-старообрядцам. Каждый ответ представляет собой красноречивую проповедь, призванную напомнить о смысле земной жизни истинного христианина и укрепить читателей в вере. Несмотря на насыщенность сочинения цитатами и точными отсылками к соответствующим фрагментам книг, «беседа» написана живым разговорным языком и ориентирована на произнесение вслух.

О том, что это сочинение было действительно востребовано местными старообрядцами, свидетельствует наличие нескольких его списков. Один из них представлен в составе тюменского рукописного комплекса В.И. Макарова из собрания Института истории СО РАН, другой, более поздний и более полный, дошел в виде отдельного сочинения, в настоящее время он хранится в рукописном собрании Тюменского областного краеведческого музея ${ }^{14}$. Наличие некоторых разночтений между списками позволяет увидеть, что переписчик дополнил и углубил первоначальную аргументацию Макарова, сделал текст еще более понятным читателю.

Таким образом, «беседы», включенные в рукописные сборники Варсонофия Ивановича Макарова, свидетельствуют о том, что дискуссии о вере с миссионерами и представителями старообрядческих согласий были важным аспектом религиозной и культурной жизни тюменской филипповской общины. Беседы пытались проводить по четко установленным и заранее оговоренным правилам, которые не всегда удавалось соблюдать. Наиболее интересные дискуссии записывались и распространялись. Тексты «бесед» были ориентированы, прежде всего, на «своих» общинников, а наличие оппонента, представляющего иную точку зрения, было лишь удобным поводом для проповеди, направленной на утверждение единоверцев в вере.

\section{СПИСОК ЛИТЕРАТУРЫ}

1. Беллюсов K. Раскол в расколе // Тобольские епархиальные ведомости. 1890. № 23-24. С. 519-520.

2. Белобородов С.А. Материалы для реконструкции библиотеки старообрядческого наставника конца XIX - начала XX вв. В.И. Макарова // Археография и источниковедение истории России периода феодализма: тез. докл. науч. конф. Свердловск, 1991. C. $17-20$.

14 Тюменский областной краеведческий музей им. И.Я. Словцова. Собрание рукописей. № 43. Описание см.: [13].
3. Духовная литература староверов востока России XVIIIХХ вв. Новосибирск, 1999. С. 395-476, 717-739.

4. Беляева О.К., Панич Т.В., Титова Л.В. Описание тюменских старообрядческих сборников из рукописных собраний ИИФиФ СО АН СССР и УрГУ // Источники по истории общественной мысли и культуры эпохи позднего феодализма. Новосибирск, 1988. С. $156-267$.

5. Беседы старообрядцев Л.Ф. Пичугина, Ф.Е. Мельникова и Д.С. Варакина. М., 1910.

6. Белобородов C.A. Поморцы и старопоморцы Ялуторовского уезда Тобольской губернии в XIX - начале XX вв. // Уральский сборник. История. Культура. Религия. Екатеринбург, 2003. T. V. C. $246-260$.

7. Темплинг А.Я. О четвертом томе из тюменских старообрядческих сборников В.И. Макарова // Древнерусское духовное наследие в Сибири. Новосибирск, 2008. Т. 1. С. 307-315.

8. Суслова Л.Н. Единоверие в Тобольской губернии во второй половине XIX - начале XX вв. // Проблемы истории России: сб. науч. тр. Екатеринбург, 2008. Вып. 7: Источник и его интерпретации. С. 212-244.

9. Ответы настоятеля Тюменской Троице-Никольской единоверческой церкви, священника Христофора Иваницкого, на вопросы наставника филипповского согласия, тюменского мещанина Варсонофия Иванова Макарова // Истина. 1883. Кн. 85. С. 1-40.

10. Понырко Н.В. Эстетические позиции писателей выговской литературной школы // Книжные центры Древней Руси. XVII век: разные аспекты исследований. СПб., 1994. С. 104-112.

11. Юхименко E.M. Невежество и премудрость в интерпретации выговских писателей-старообрядцев // ТОДРЛ. СПб., 2004. T. 55. C. $508-516$

12. Журавель О.Д. Литературное творчество старообрядцев XVIII - начала XXI вв.: темы, проблемы, поэтика. Новосибирск, 2012. $441 \mathrm{c}$

13. Покровский Н.Н. Рукописи и старопечатные книги Тюменского областного музея // Археография и источниковедение Сибири. Новосибирск, 1975. [Вып.1]. С. 144-148.

\section{REFERENCES}

1. Bellyusov K. A schism inside the Schism. Tobolskie eparkhialnye vedomosti. 1890, N 23-24, pp. 519-520. (In Russ.).

2. Beloborodov S.A. Materials for reconstrucing the library of V.I. Makarov, an Old-Believers' religious community leader of the late XIX - early XX centuries. Arkheografiya i istochnikovedenie istorii Rossii perioda feodalizma: tezisy dokladov nauchnoi konferentsii. Sverdlovsk, 1991, pp. 17-20. (In Russ.).

3. Ecclesiastic literature of the Old-Believers of Eastern Russia in the XVIII-XX centuries. Novosibirsk, 1999, pp. 395-476, 717-739. (In Russ.).

4. Belyaeva O.K., Panich T.V., Titova L.V. Descriptions of Tumen Old-Believers' collections from manuscript collections of the Institute of History and Philosophy of the Siberian Branch of the Russian Academy of Science and the Ural State University. Istochniki po istorii obschestvennoi mysli i kultury epokhi pozdnego feodalizma. Novosibirsk, 1988, pp. 156-267. (In Russ.).

5. Dialogues of Old-Believers L.F. Pichugin, F.E. Melnikov, and D.S. Varakin. Moscow, 1910. (In Russ.).

6. Beloborodov S.A. Portsy and Old-Pomortsy of Yalutorovsk district of Tobolsk province in XIX - early XX centuries. Uralskii sbornik. Istoriya. Kultura. Religiya. Ekaterinburg, 2003, pp. 246-260. (In Russ.)

7. Templing A.Ya. On fourth volume of I.V. Makarov's Tumen OldBelievers' collected works. Drevnerusskoe dukhovnoe nasledie v Sibiri. Novosibirsk, 2008, vol. 1, pp. 307-315 (In Russ.).

8. Suslova L.N. Edinoverie in Tobolsk province in the second half of XIX - early XX centuries. Problem istorii Rossii. Vyp. 7: Istochnik i ego interpretatsii. Sbornik nauchnyh trudov. Ekaterinburg, 2008, pp. 212-244 (In Russ.). 
9. Answers of Christopher Ivanitskii, a senior priest of Tumen Troitsk-Nikolsk Church of the edinovertsy, to questions of Varsonovii Ivanivich Makarov, a community leader of Philipovtsy denomination, a Tumen bourgeois. Istina, 1883. Book 85, pp. 1-40 (In Russ.).

10. Ponyrko N.V. Aesthetic views of writers belonging to the Vyg literary tradition. Knizhnye tsentry Drevnei Rusi. XVII vek: Raznye aspekty issledovanii. St. Petersburg, 1994, pp. 104-112 (In Russ.).

11. Yukhimenko E.M. Ignorance and wisdom in the Vyg OldBelievers writers' opinion. TODRL. St. Petersburg, 2004, vol. 55, pp. 508-516 (In Russ.).
12. Zhuravel'O.D. Literary works of Old-Believers of the XVIII early XXI centuries: subjects, issues, and poetics. Novosibirsk, 2012 (In Russ.).

13. Pokrovsky N.N. Manuscripts and early books of the Tyumen regional museum. Arkheografiya i istochnikovedenie Sibiri. Novosibirsk, 1975, [Vyp.1]. pp. 144-148 (In Russ.)

Статья принята редакиией 09.07.2015

DOI: $10.15372 / \mathrm{HSS} 20150305$

УДК 279.99-285.4

\title{
Н.А. СТАРУХИН
}

\section{«ПОСЛЕДНИЕ ВРЕМЕНА» В СОЧИНЕНИИ «ПОКАЗАНИЕ ИСТИНЫ» СТАРОВЕРА-«АВСТРИЙЦА» Г.А. СТРАХОВА}

\author{
Николай Алексеевич Старухин, канд. ист. наук, \\ научный сотрудник, \\ РФ, 630090, г. Новосибирск, ул. Николаева, 8 \\ Институт истории СО РАН, \\ e-mail: prognostika@mail.ru
}

\begin{abstract}
В статье рассматриваются эсхатологические построения, изложенные в сочинении середины 1890-х гг. «Показание истины», которое атрибутируется писателю-сибиряку Г.А. Страхову. Анализируются особенности эсхатологических взглядов писателя, источники, на которые он опирался. Это позволяет расширить представления о литературе и идеологии белокриницкого («австрийского») согласия во второй половине XIX в. Делается вывод, что круг вопросов, обозначенных автором, вполне соответствовал уровню внутренней и внешней полемики староверов указанного периода. Показано, что в ряде выводов сибирский писатель заходит гораздо дальше разработок других белокриницких апологетов. Это касается трактовки чувственного понимания природы антихриста, оценки деятельности российских самодержцев, осмысления творческого наследия раннего староверия. Несколько по-иному оценивается им тема преследований староверов, и, соответственно, проблема их взаимоотношений с властями, собственной иерархией. Последнее в значительной мере сближает Г.А. Страхова с радикальным крылом «австрийцев».
\end{abstract}

Ключевые слова: старообрядчество, белокриницкое согласие, полемика, эсхатология, апологетика, литература, идеология.

\section{N.A. STARUKHIN}

\section{"THE END TIMES" IN THE "TESTIMONY OF TRUTH" BY AN "AUSTRIAN" OLD-BELIEVER G.A. STRAKHOV}

Nicolay A. Starukhin,

Candidate of Historical Sciences, Researcher, Institute of History SB RAS

8, Nikolaeva Str., Novosibirsk, 630090, Russia, e-mail: prognostika@mail.ru

The article introduces for scientific use one of the copies of a polemic writing by a Siberian peasant writer Grigoriy Arefyevich Strakhov from the collection of the Institute of History, SB RAS. The copy has been acquired in one of the Old Believers' settlements as a result of archaographical fieldwork. Using G.A.Strakhov's writing as an example the author considers eschatological issues that remained invariably topical in the Old-Believer literature and perfectly characterized specifics of historiosophy and ideology of the people at the grassroots level of Belokrinitsky Agreement - one of the last Old Believer agreements. Moreover, addressing the range of eschatological problems (which is a separate research problem) allows to deepen our understanding of both Old-Believers' internal and interfaith polemics, as well as the late Old Believers' political essays written in the latter half of the XIX century.

(C) Старухин Н.A., 2015 